\section{Coupling of HRT II and AS-OCT to evaluate corneal endothelial cell loss and in vivo visualization of the Ahmed glaucoma valve implant}

E Mendrinos, A Dosso, J Sommerhalder and T Shaarawy
Department of

Ophthalmology, Geneva University Hospitals,

Geneva, Switzerland

Correspondence:

T Shaarawy,

Department of

Ophthalmology,

22 rue Alcide Jentzer,

1211 Geneva 14,

Switzerland

Tel: + 0041223828 400;

Fax: + 0041223828382

E-mail: tarek.shaarawy@

hcuge.ch

Received: 21 May 2008 Accepted in revised form: 23 September 2008

Published online: 24

October 2008

This study was presented in part at the 6th International Glaucoma Symposium-IGS, 28-31 March 2007, Athens, Greece and at the World Glaucoma Congress, 18-21 July 2007, Singapore

\begin{abstract}
Aims To report corneal endothelial cell loss and in vivo visualization of the Ahmed glaucoma valve implant in eyes with refractory glaucoma.

Methods Ten eyes underwent Ahmed valve implant surgery and were followed-up for 12 months. Data collected included intraocular pressure (IOP), number of antiglaucoma medications and surgery-related complications. At 6 and 12 months postoperatively, the intracameral length of the drainage tube (ICL) and the distance between the tube and the cornea ( $\mathrm{T}-\mathrm{C}$ distance), and the iris (T-I distance) were assessed using anterior segment optical coherence tomography (AS-OCT). Heidelberg cornea tomograph II (HRT II) was used to measure the corneal endothelial cell density.

Results Mean ( \pm SEM) preoperative IOP was $29.5 \pm 4 \mathrm{mmHg}$. Mean postoperative IOP was $11.6 \pm 2$ at 12 months $(P<0.01)$. Over a 6-month period, mean corneal endothelial loss was $7.9 \% \pm 2.5$ in the central and $7.5 \% \pm 2.4$ in the peripheral cornea $(P<0.01)$. There was no correlation between central or peripheral corneal endothelial cell loss and the T-C, T-I distance or the ICL of the tube. Conclusions Corneal endothelial cell loss occurs following Ahmed valve implant surgery, this appears to be multifactorial. AS-OCT and HRT II are promising methods for the follow-up of patients with a glaucoma drainage device.

Eye (2009) 23, 1836-1844; doi:10.1038/eye.2008.321; published online 24 October 2008
\end{abstract}

Keywords: Ahmed valve; corneal endothelial cell loss; anterior segment OCT; in vivo confocal microscopy

\section{Introduction}

Refractory glaucomas refer to a group of glaucomas resistant to medical treatment and/or conventional surgical filtering approaches, and alternative surgical techniques should be considered. Glaucoma drainage device (GDD) implantation surgery, which creates an alternative pathway for aqueous outflow, seems to be a promising alternative in such cases. ${ }^{1}$

However, corneal endothelial loss leading to corneal decompensation and corneal graft failure are major limitations to the success rate associated with GDD implantation and account for most of the surgical failures. ${ }^{2,3}$ There is only one study published in 1993 providing data on corneal endothelium cell counts after Molteno single-plate implantation based on specular microscopy. ${ }^{4}$

The purpose of this study was to further investigate the impact of GDD implantation and more specifically that of the Ahmed glaucoma valve on the corneal endothelium in the light of new anterior segment (AS) imaging techniques as well as to report short-term results with this drainage device in eyes with refractory glaucoma. We used in vivo confocal microscopy for monitoring endothelial cell changes and the Visante optical coherence tomography (OCT), a commercially available AS-OCT for in vivo visualization of the drainage tube. We report here our preliminary results in 10 eyes with a follow-up of 12 months. 


\section{Materials and methods}

In all, 10 eyes of 10 consecutive patients who underwent Ahmed valve implant surgery were included in the study. All patients had refractory glaucoma that did not respond to maximal medical treatment, transcleral diode cyclophotocoagulation, and/or previous filtering procedures. Data collected included demographic information, type of glaucoma, intraocular pressure (IOP), number of antiglaucoma medications and GDD implantation-related complications. Slit-lamp AS examination and funduscopy were performed at each visit. Postoperative follow-up examinations were performed on the first and third postoperative day, at weeks 1 and 2, months 1,2, 3, 4, 6 and 12. At the follow-up visist of 6 and 12 months, all patients underwent AS-OCT and in vivo confocal microscopy of the cornea in the study eye.

\section{Surgical technique}

All patients were operated by the same surgeon under topical anaesthesia (TS). The Ahmed glaucoma valve-FP7 model was used and the superotemporal quadrant was chosen for the valve implantation. Briefly, this surgery was carried out as follows: a fornix-based conjunctival flap was created, with the Tenon's capsule also lifted at the same time. Dissection under Tenon's capsule was continued posteriorly beyond the intermuscular septum with closed Westcott scissors, and retiring them open to widen the space for the valve. Ahmed's valve was primed before insertion; balanced salt solution was injected with a 27 -gauge $(G)$ cannula inserted 3-5 mm into the tube until it separated the silicone foils and exited towards the body. The valve's body was fixed with a preplaced 7-0 silk suture 8-10 mm behind the limbus. A 23-G needle was used to enter the anterior chamber (AC) at the posterior limbus and parallel to the iris plane. The tube was cut in a bevelled manner so that the bevel faced the corneal endothelial surface and had approximatively $2-4 \mathrm{~mm}$ intracameral length. An intrascleral tunnel was formed and the tube was placed through it before entering the AC to maintain it in a stable position. After the tube was positioned, the conjunctiva and Tenon's capsule were closed with absorbable sutures.

\section{Visante OCT}

Each eye was imaged with the commercially available Visante OCT (Visante OCT Carl Zeiss Meditec., Dublin, CA, USA). The patient was asked to look slightly downwards and the upper eyelid was gently retracted by the examiner. The drainage tube was imaged with the

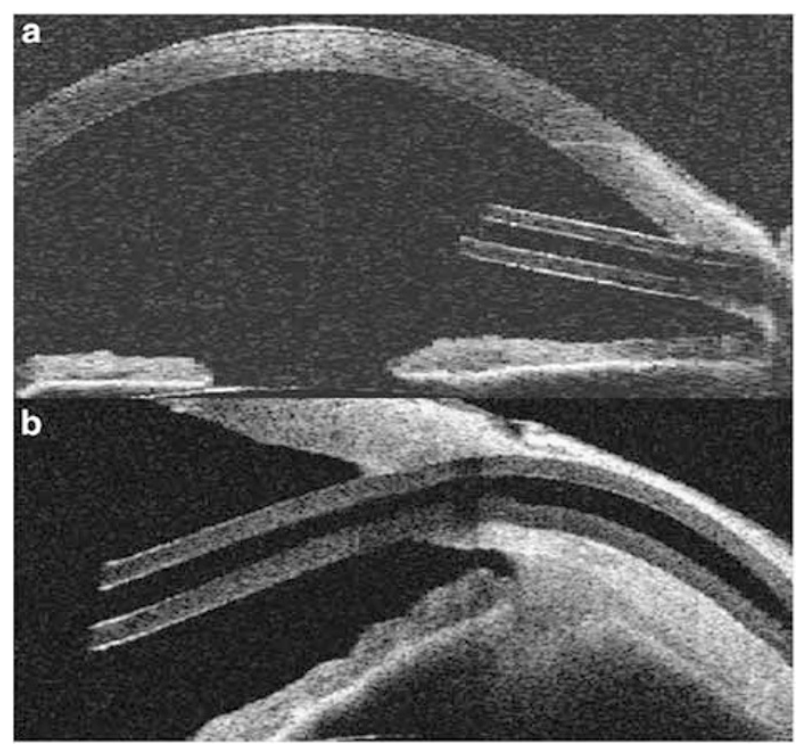

Figure 1 (a) Visante OCT of the anterior segment following Ahmed valve implantation. Note the presence of the drainage tube into the anterior chamber. The tube is well positioned; its intracameral length and the distances between the tube and the cornea and iris can be measured. (b) High-resolution scan of the Ahmed's valve drainage tube showing its intrascleral and intracameral courses.

'AS single scan' protocol by a single examiner after alignment of the scan line parallel to the axis of the drainage tube. In some cases, a 'high-resolution scan' was also obtained (Figure 1). Using a two-dimensional image recorded by the Visante OCT, the following parameters were measured with the caliper tool of the device's software: intracameral length of the drainage tube (ICL), distance between the extremity of the tube and the posterior endothelial surface of the cornea (T-C distance) and the anterior surface of the iris (T-I distance). The distances were automatically calculated when these landmarks were manually located.

\section{In vivo confocal microscopy}

In vivo confocal microscopy images were obtained using the Heidelberg retina tomograph II rostock corneal module (HRT II RCM, Heidelberg Engineering GmbH, Dossenheim, Germany). During examination, all patients were asked to fixate on a distant target aligned to enable examination of the central cornea and were then asked to look gently downwards to enable the examination of the superotemporal cornea. An experienced observer selected one frame of the corneal endothelium where the images appeared clearest. Each frame comprised a minimum of 50 cells, and cell counts were executed manually. The endothelial cell density counts were performed by software provided with the microscope. 
Central (CED) and peripheral (superotemporal) corneal endothelial cell density (PED) in the proximity of the tube were assessed. Percentage of endothelial cell loss between 6 and 12 months after surgery was calculated for each eye. Mean and median percentages of endothelial cell loss values were then calculated.

AS-OCT measurements and ECD counts were performed by two different examiners, so that each examiner was not aware of the results of the measurements performed by the other examiner, thus limiting any bias.

The study was performed in conformance with the principles of the Declaration of Helsinki and with the Swiss federal laws. All patients provided signed informed consent before surgery. Because AS-OCT and in vivo confocal microscopy are performed for routine clinical care in our department and no additional procedure was performed for research purposes alone, no specific consent was required by the Ethics Committee of the Geneva University Hospitals. However, all patients were informed of the aims of recording these data and their oral consent was obtained before undergoing AS-OCT and HRT II RCM.

\section{Statistical analysis}

Wilcoxon tests were used to compare the means of preoperative and postoperative IOP, numbers of medications, endothelial cell densities, ICLs of the drainage tube, and T-C and T-I distances. Pearson correlations were used to evaluate whether $\mathrm{T}-\mathrm{C}$ and $\mathrm{T}-\mathrm{I}$ distances or the ICL of the drainage tube were correlated with central and peripheral endothelial cell density changes following surgery. Differences or correlations were considered statistically significant, when $P$-value was less than 0.05. Data are presented as mean values $\pm S E M$.

\section{Results}

Median age at the date of operation was 45-years old (range: 17-85 years). Eight patients were male and two were female. There were four right and six left eyes. Six eyes were pseudophakic, two were aphakic, and two were phakic. Indications for surgery were post-traumatic glaucoma (two cases), glaucoma secondary to multiple previous vitrectomy procedures (three cases), pseudoexfoliative glaucoma (two cases), open-angle glaucoma (two cases), and glaucoma secondary to Fuchs iridocyclitis (one case). The mean preoperative IOP was $29.5 \pm 3.8 \mathrm{mmHg}$ (range: $17-58 \mathrm{mmHg}$ ). There were no signs of AC inflammation, either cells or flare as detected by biomicroscopy. The patient with Fuch's iridocyclitis had keratic precipitates on the corneal endothelium.
Mean postoperative IOP was significantly lower. It measured $14.2 \pm 1.5 \mathrm{mmHg}$ at 6 months and $11.6 \pm 2 \mathrm{mmHg}$ at 12 months $(P<0.01)$. Mean number of antiglaucoma medications significantly decreased from $3.3 \pm 1.3$ (range: $0-5$ ) before the operation to $0.6 \pm 0.9$ (range: $0-2 ; P<0.01$ ) at 12 months. There were no cases of early or late hypotony, choroidal detachment, and shallow/flat AC following surgery. Surgery-related complications included encapsulated bleb (one eye), cornea-tube contact (one eye; Figure 2), and hyphaema (one eye; Fuchs iridocyclitis). These complications were successfully managed with needling with mitomycin C in the first case and with partial tube resection in the second case. Hyphaema resolved spontaneously after 10 days in the third case. Visual acuity remained stable or improved in all eyes but one, which lost light perception.

Six months after Ahmed valve implant surgery, mean $\mathrm{T}-\mathrm{C}$ distance and $\mathrm{T}-\mathrm{I}$ distance were $1.2 \pm 0.4 \mathrm{~mm}$ (range:
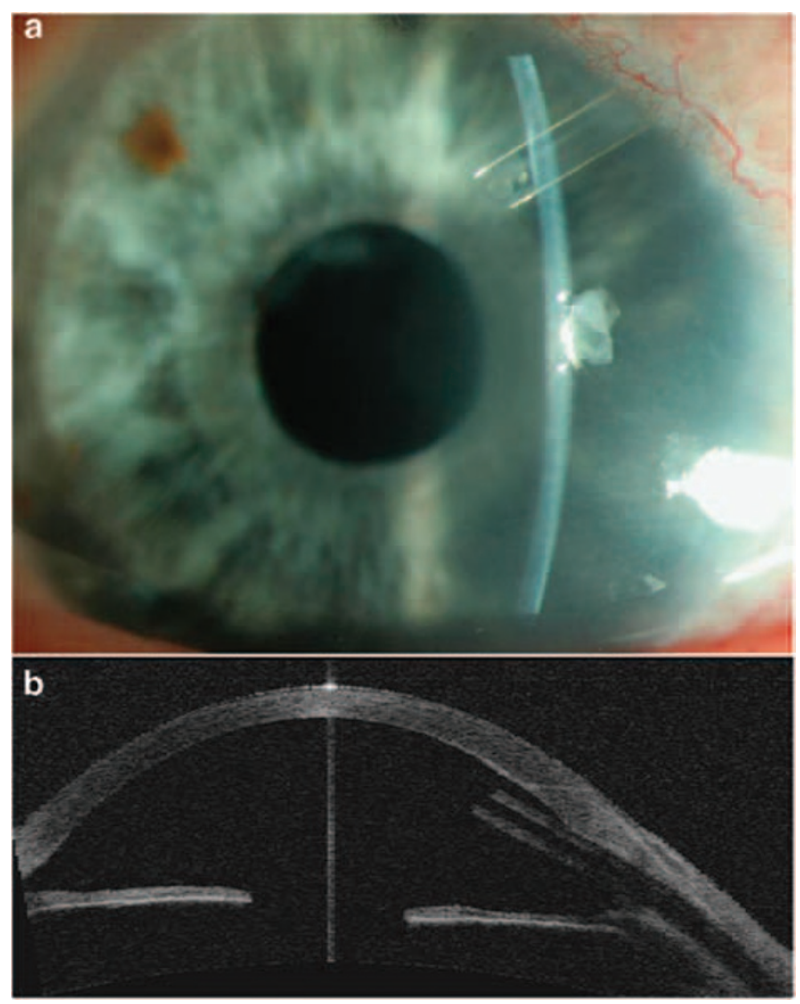

Figure 2 (a) Slit-lamp anterior segment photography showing the drainage tube into the anterior chamber of a patient who underwent Ahmed valve implant surgery. (b) Visante OCT of the anterior segment of the same patient providing details about the anatomic relationship between the drainage tube and the cornea. Note the contact of the tube with the limbus; the distance between the extremity of the tube and the cornea was measured to be $0.6 \mathrm{~mm}$. Corneal endothelial cell density in proximity of the tube measured by in vivo confocal microscopy was 590 cells/ $\mathrm{mm}^{2}$. On the basis of the results given by AS-OCT and confocal microscopy, this patient was elicited to be treated by partial tube resection and repositioning. 
0.6-1.8 mm) and $1.4 \pm 0.3 \mathrm{~mm}$ (range: $1-2.1 \mathrm{~mm}$ ), respectively and mean ICL of the tube was $2.9 \pm 0.5 \mathrm{~mm}$ (range: $2.2-3.5 \mathrm{~mm}$ ). To see whether measurements are repeatable, they were performed twice. The difference between the two measurements by AS-OCT was not significant; for the second measurements, mean $\mathrm{T}-\mathrm{C}$ distance, T-I distance, and ICL were $1.2 \pm 0.4 \mathrm{~mm}$ $(P=0.3)$ and $1.3 \pm 0.3 \mathrm{~mm}(P=0.27)$ and $2.8 \pm 0.4 \mathrm{~mm}$ $(P=0.52)$, respectively.

AS-OCT measurements were performed again 6 months later. Mean T-C and T-I distances and ICL of the tube were now $1.2 \pm 0.4 \mathrm{~mm}$ (range: $0.9-1.7 \mathrm{~mm}$ ), $1.3 \pm 0.3 \mathrm{~mm}$ (range: $0.9-2.0 \mathrm{~mm}$ ), and $2.8 \pm 0.6$ (range: 1.9-3.4 mm), respectively. There was no significant change for the three parameters, indicating a stable position of the drainage tube.

Table 1 lists the percentage of endothelial cell loss and the CED and PED values for each patient at 6 and 12 months postoperatively. Over a 6-month period, the median percentage of the endothelial cell loss was $7.4 \%$ in the central and $6.2 \%$ in the peripheral cornea; mean $( \pm$ SEM) values were $7.9 \pm 2.5 \%$ and $7.5 \pm 2.4 \%$, respectively. For both locations, this cell loss was significant $(P<0.01)$. There was no statistically significant difference between CED and PED at 6 and 12 months after surgery $(P>0.1)$. No significant correlation could be found between central or peripheral corneal endothelial cell loss and the T-C and T-I distances or the ICL of the tube (Figures 3 and 4).

\section{Discussion}

Aqueous shunting procedures are used for uncontrolled glaucoma whenever previous filtration surgery has failed or as a primary procedure for some refractory glaucomas. In 1993, the Ahmed glaucoma valve
(New World Medical, Rancho Cucamonga, CA, USA) was introduced, a pressure-sensitive, unidirectional valve that is designed to open when the IOP is $8 \mathrm{mmHg}$ to prevent early postoperative hypotony. ${ }^{5}$ This is a potential advantage over GDDs with no set resistance mechanism, as postoperative flat or shallow AC with tube-cornea touch can cause significant corneal endothelial damage. ${ }^{6,7}$

Corneal complications have been reported in up to $30 \%$ of the patients undergoing Ahmed valve implantation with long-term follow-up; $56 \%$ of the eyes with corneal grafts and $16 \%$ of the eyes without corneal graft had corneal oedema or decompensation following surgery. ${ }^{2}$ Al-Torbak ${ }^{8}$ reported a $50 \%$ graft success rate 3 years after simultaneous penetrating keratoplasty and Ahmed valve implantation, and Coleman et al ${ }^{9}$ reported a $62 \%$ graft success rate at 20 months after Ahmed valve implantation and prior or concurrent penetrating keratoplasties.

The mechanism for endothelial cell loss after GDD implantation is not fully understood and is probably multifactorial. Preoperative factors, such as earlier surgeries and episodes of inflammation together with chronically or episodes of acute elevated IOP, can all contribute to endothelial cell loss and subsequent corneal decompensation in the postoperative period. The degree and duration of elevated IOP has been shown to result in significant endothelial cell loss. Endothelial cell loss of 10-33\% has been reported following an acute attack of angle-closure glaucoma, and $77 \%$ cell loss when the attack lasted more than 12 days. ${ }^{10}$ This together with postoperative factors, such as inflammation and cornealtube touch, either directly or during eye rubbing or blinking, may explain progressive endothelial damage.

Another factor that should be taken into consideration is the state of the endothelial cells before GDD

Table 1 Endothelial cell density (cells $/ \mathrm{mm}^{2}$ ) and the percentage change between 6 and 12 months after surgery

\begin{tabular}{|c|c|c|c|c|c|c|c|c|}
\hline $\begin{array}{l}\text { Patient } \\
\text { no. }\end{array}$ & $\begin{array}{l}\text { CED } 6 \\
\text { months }\end{array}$ & $\begin{array}{l}\text { PED } 6 \\
\text { months }\end{array}$ & $\begin{array}{l}\text { CED } 12 \\
\text { months }\end{array}$ & $\begin{array}{l}\text { PED } 12 \\
\text { months }\end{array}$ & $\begin{array}{l}\text { CED } \\
\text { change }\end{array}$ & $\begin{array}{l}\text { PED } \\
\text { change }\end{array}$ & $\begin{array}{c}\text { Percentage of CED } \\
\text { change }\end{array}$ & $\begin{array}{c}\text { Percentage PED } \\
\text { change }\end{array}$ \\
\hline 1 & 2731 & 2462 & 2336 & 2133 & -395 & -329 & -14.5 & -13.4 \\
\hline 2 & 2023 & 1853 & 1861 & 1760 & -162 & -93 & -8.0 & -5.0 \\
\hline 3 & 1196 & 590 & 1170 & 524 & -26 & -66 & -2.2 & -11.2 \\
\hline 4 & 2093 & 1973 & 1831 & 1968 & -262 & -5 & -12.5 & -0.3 \\
\hline 5 & 1846 & 2373 & 1756 & 1974 & -90 & -399 & -4.9 & -16.8 \\
\hline 6 & 3287 & 3350 & 2929 & 3150 & -358 & -200 & -10.9 & -6.0 \\
\hline 7 & 1855 & 1880 & 1768 & 1835 & -87 & -45 & -4.7 & -2.4 \\
\hline 8 & 2172 & 1842 & 2049 & 1709 & -123 & -133 & -5.7 & -7.2 \\
\hline 9 & 1226 & 1141 & 1143 & 1068 & -83 & -73 & -6.8 & -6.4 \\
\hline 10 & 2158 & 1968 & 1964 & 1850 & -194 & -118 & -9.0 & -6.0 \\
\hline Mean & 2059 & 1943 & 1881 & 1797 & -178 & -146 & -7.9 & -7.5 \\
\hline$\pm \mathrm{SEM}$ & 197 & 234 & 164 & 215 & 39 & 40 & 2.5 & 2.4 \\
\hline
\end{tabular}

$\mathrm{CED}=$ central endothelial cell density; $\mathrm{PED},=$ peripheral endothelial cell density. 

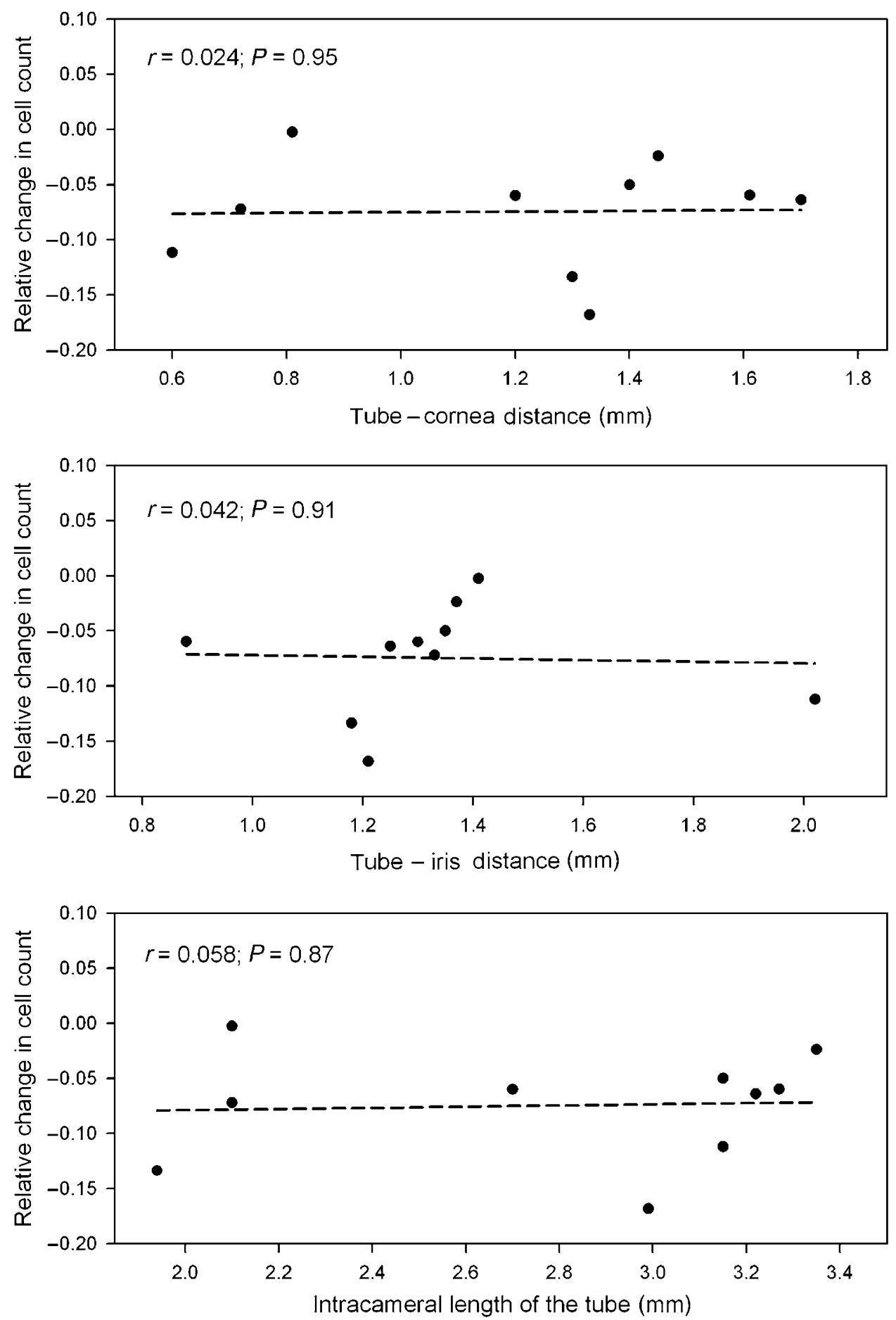

Figure 3 Postoperative relative endothelial cell density changes (between 6 and 12 months) in the central cornea vs tube-cornea distance, tube-iris distance, and intracameral length of the tube (measured at 12 months). Dashed lines represent Pearson correlations. Correlation coefficients $(r)$ were tested against zero to determine whether these correlations were significant or not.

implantation. If the endothelial cells are already compromised, the postoperative endothelial cell loss is just a reflection of the natural course of the disease vs GDD implant surgery compromising the endothelial status. Moreover, glaucoma patients and patients with chronic anterior uveitis have a mean corneal endothelial density lower than the normal population and decreased resistance to endothelial traumas. ${ }^{11,12}$ Finally, there may be foreign body inflammation secondary to the silicone tube itself; such a chronic low-grade inflammation could 

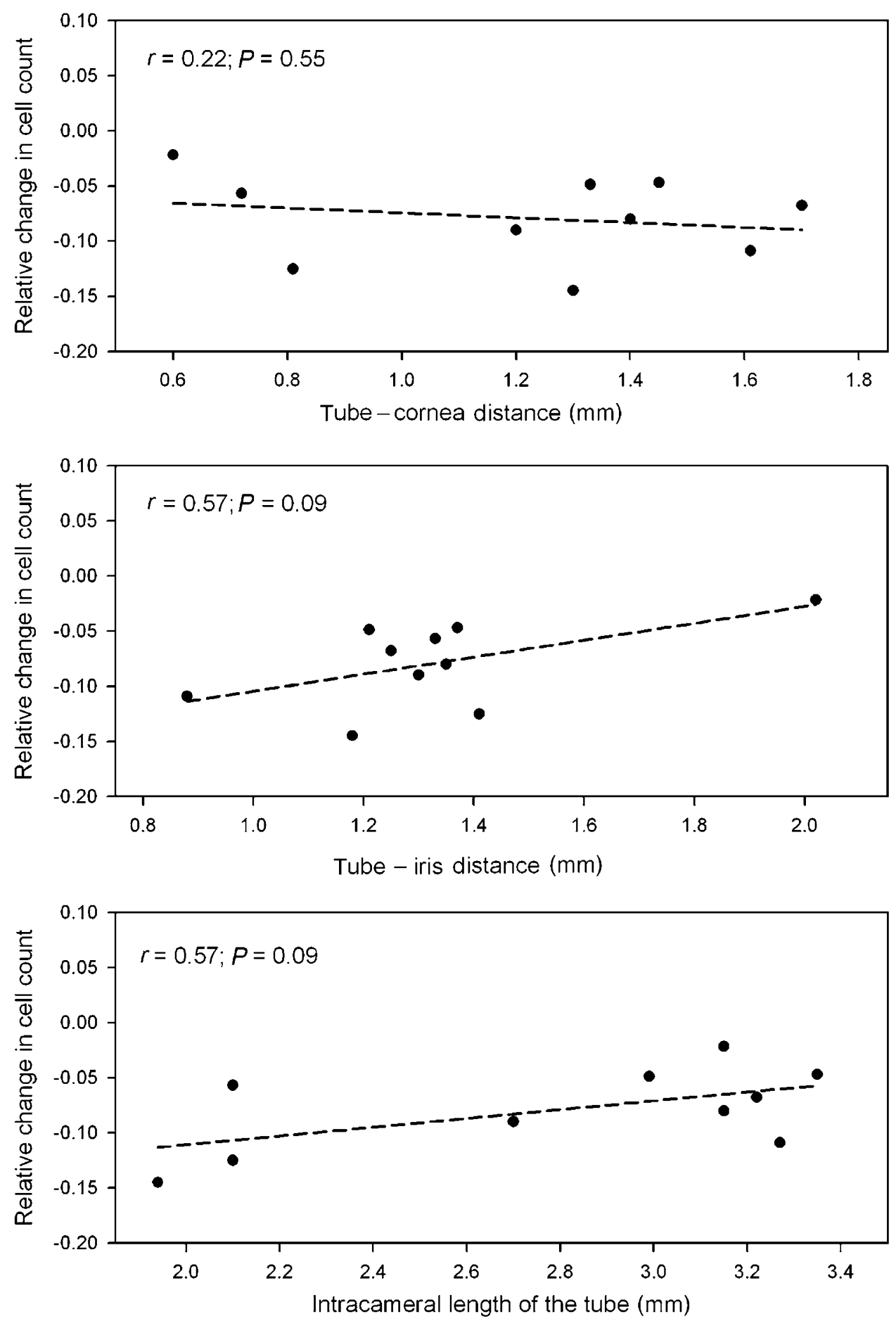

Figure 4 Postoperative relative endothelial cell density changes (between 6 and 12 months) in the peripheral cornea vs tube-cornea distance, tube-iris distance, and intracameral length of the tube (measured at 12 months). Dashed lines represent Pearson correlations. Correlation coefficients $(r)$ were tested against zero to determine whether these correlations were significant or not.

compromise endothelial health. ${ }^{13}$ Immunologic graft rejection precipitated by chronic blood-aqueous barrier breakdown after GDD implantation may also contribute to the occurrence of graft failure. ${ }^{14}$
To the best of our knowledge, there has been a single report by McDermott et $a l^{4}$ on endothelial cell changes following the uneventful Molteno implant surgery. The authors used specular microscopy to measure central 
endothelial cell density in 19 patients and found no clinically significant endothelial cell loss after a follow-up of 10 months. They did not perform regional specular microscopy in the area of the tube. In our study, we found a mean endothelial cell loss of approximatively $8 \%$ for the central and peripheral cornea during a 6-month period after surgery, which is higher than the reported age-related endothelial cell loss, ${ }^{15}$ but comparable or even less to that following cataract extraction ${ }^{16,17}$ or other glaucoma filtering procedures. $6,7,18$

Smith et $a l^{6}$ calculated a mean central endothelial cell loss ranging from 1.6 to $54.8 \%$ three months after glaucoma surgery, correlated with postoperative AC depth and intraoperative corneal touch. Fiore et $a l^{7}$ reported a $12.4 \%$ and a $11.6 \%$ reduction in peripheral and central endothelial cell counts after 4-6 months of filtration surgery in eyes with shallow AC and iridocorneal touch. Sihota et al $^{18}$ reported a $14 \%$ decrease in mean ECD after 3 months of trabeculectomy with mitomycin C. More recently, Arnavielle et al ${ }^{19}$ found a statistically significant endothelial cell loss of 7 and $10.6 \%$ in the central and superior cornea, respectively, 3 months following trabeculectomy, and of 9.6 and $11.9 \%$ at 12 months. Deep sclerectomy with no penetration into the AC resulted in less endothelial cell loss, 2.6 and $4.5 \%$ in central and superior cornea, respectively at 3 months, and 3.3 and $5.2 \%$, respectively at 12 months.

Numerous studies evaluating the endothelial cell changes and densities after cataract extraction have been published. ${ }^{16,17,20-22}$ However, the incision site, operative technique, and measurement methods vary and lead to different results. Recently, in a large series of 433 patients, Bourne $e t a l^{16}$ found a mean reduction in endothelial cell count of 16.1 and $14.2 \% 12$ months following phacoemulsification and extracapsular cataract extraction, respectively. Walkow et $a l^{17}$ reported a mean central endothelial cell loss of $8.5 \%$ after 12 months of phacoemulsification. The mean endothelial cell loss was $11.4 \%$ in the superior quadrant.

The tube position remained stable during the followup period, and the endothelial cell loss was found to be significant between 6 and 12 months following surgery. However, there was no correlation between the endothelial cell loss and the T-C and T-I distances or the ICL of the tube, neither in the central nor in the superotemporal cornea. These results argue in favour of an acceptable endothelial tolerance of the drainage tube. Nevertheless, we cannot rule out that continued micromotions of the tube relative to the cornea, transmitted from repeated minor shearing of the implant in relation to the surrounding tissues, and suboptimal tissue compatibility could lead to a continuing low-grade inflammation and to progressive endothelial cell loss. Trauma to the iris may induce breakdown of the blood- aqueous barrier and contribute to persistent inflammation in the AC. Chronic inflammation has been shown to increase endothelial permeability and decrease $\mathrm{Na}+/ \mathrm{K}+$ ATPase pump site density in animal models. ${ }^{23}$ Superimposed to preoperative compromised endothelial cell health, eventual intraoperative endothelial damage and damage in the early postoperative period in complicated cases with poor tube positioning and/or AC shallowing is the most likely mechanism of corneal endothelial cell failure following GDD surgery.

To our knowledge, this study is the first one that was conducted by the means of new imaging modalities in an attempt to establish in patients with refractory glaucoma whether corneal endothelial loss is related to the drainage device itself. In vivo confocal microscopy is becoming a useful diagnostic tool for corneal imaging, ${ }^{24}$ and has been reported to be a reliable and wellreproducible method for the measurement of the endothelial cell density. ${ }^{25,26}$ Klais et $a l^{27}$ compared corneal endothelial cell counts in 42 normal eyes obtained by confocal and specular microscopy and found measurements to be comparable with both methods. Similarly, Kitzmann et $a l^{28}$ showed that endothelial cell density measured from the images recorded by confocal and specular microscopy were not significantly different from each other when the same programme was used for the measurement.

The aforementioned studies evaluated white light in vivo confocal microscopy. HRT II is a laser scanning confocal microscope. We found one study comparing HRT II to both white light confocal microscope and specular microscope in normal and pathological corneas. ${ }^{29}$ HRT II was found to overestimate endothelial cell counts compared with both white light confocal microscopy and specular microscopy, especially at high cell densities, suggesting that these methods cannot be used interchangeably for endothelial cell count for the same patient. Moreover, when comparing studies that performed ECD measurement with specular microscopy between them, significantly different ECD values may occur. ${ }^{30-32}$ However, we report and compare our results with other studies using specular microscopy in terms of percentage change, measured in each case with the same method, and therefore allowing for valid comparisons.

Confocal microscopy has several advantages over specular microscopy. ${ }^{33-35}$ As a result of the optical principles involved in specular microscopy, there are limitations to the use of this instrument. The cornea should be transparent and the endothelial surface should be regular and smooth in order to obtain specular reflection. In contrast, the pinpoint focusing intrinsic to confocal optics and the composite nature of the images, obtained ensure that confocal biomicroscopy is not 
affected by the nature of the endothelial surface. ${ }^{36}$ Hara et $a l^{33}$ compared the clinical efficacy of confocal biomicroscopy with that of non-contact specular microscopy for the evaluation of the corneal endothelium. Although clear images of corneal endothelial cells, allowing the determination of cell density, were obtained for all eyes evaluated by confocal biomicroscopy, clear images were obtained for only $36.4 \%$ of these eyes by non-contact specular microscopy. Patients undergoing GDD, usually suffer from refractory glaucomas, have already undergone one or more antiglaucoma surgeries, and thus may present with some degree of corneal opacification. In those eyes, specular microscopy may not be informative about endothelial cell imaging and counting.

Other advantages of confocal biomicroscopy include the fact that it allows the examination of all cellular components of the cornea layer by layer in a noninvasive manner; data on corneal thickness, corneal nerve density, and keratocyte density can be examined from the same scan. ${ }^{36,37}$ Information that otherwise would require more than one instrument to collect can be obtained from only a few scans with one instrument. Histologic information based on the appearance and density of cells can also be derived by confocal images. ${ }^{36}$ The ability of a confocal biomicroscope to focus on different optical slices and to reveal the threedimensional structure of the cornea also renders it superior to and of wider applicability than the specular microscope. $^{38}$

AS-OCT was recently introduced to provide a noncontact approach for AS imaging. It is designed to image the shape, size, and position of AS structures, take precise measurements of the distances between them, and has proved to be an accurate and reliable device for these purposes. ${ }^{39,40}$ The position and patency of an aqueous shunt in the AC may be difficult to determine by slit-lamp examination or by gonioscopy whenever the corneal clarity is reduced or the intraluminal portion of the shunt is short. Displacement and obliteration of the tube can result in postoperative IOP elevation, which may be difficult to detect in the presence of corneal opacities. ${ }^{41-43}$ AS-OCT can be used to visualize AC tubes in the presence of corneal oedema that precludes an adequate view or in cases where the tube is retracted into the cornea. In such cases, AS-OCT is useful in identifying shunt patency and position, which helps guide clinical and surgical decision making. ${ }^{42,43}$

These new imaging techniques have spurred a rapidly increasing number of important research applications. ${ }^{44}$ More specifically, in our study, they proved to be useful tools in visualizing in vivo the anatomic relationships between the drainage tube and the AC structures, in monitoring endothelial cell loss following GDD surgery, and in postoperative management (Figure 2).

Our study is limited by its small sample size and lack of preoperative data on corneal endothelial cell density. On the basis of our results and subject to the limitations of our study, endothelial cell loss following Ahmed valve implantation may not be directly related to the drainage device itself, and it is possible that many factors contribute to this. Further research is necessary in this field to elucidate the influence of GDD on the central and peripheral corneal endothelial cell density.

\section{References}

1 Hong CH, Arosemena A, Zurakowski D, Ayyala RS. Glaucoma drainage devices: a systematic literature review and current controversies. Surv Ophthalmol 2005; 50: 48-60.

2 Topouzis F, Coleman AL, Choplin N, Bethlem MM, Hill R, $\mathrm{Yu} F$ et al. Follow-up of the original cohort with the Ahmed glaucoma valve implant. Am J Ophthalmol 1999; 128: 198-204.

3 Kwon YH, Taylor JM, Hong S, Honkanen RA, Zimmerman $\mathrm{MB}$, Alward WL et al. Long-term results of eyes with penetrating keratoplasty and glaucoma drainage tube implant. Ophthalmology 2001; 108: 272-278.

4 McDermott ML, Swendris RP, Shin DH, Juzych MS, Cowden JW. Corneal endothelial cell counts after Molteno implantation. Am J Ophthalmol 1993; 115: 93-96.

5 Bhatia LS, Chen TC. New Ahmed valve designs. Int Ophthalmol Clin 2004; 44: 123-138.

6 Smith DL, Skuta GL, Lindenmuth KA, Musch DC, Bergstrom TJ. The effect of glaucoma filtering surgery on corneal endothelial cell density. Ophthalmic Surg 1991; 22: 251-255.

7 Fiore PM, Richter CU, Arzeno G, Arrigg CA, Shingleton BJ, Bellows AR et al. The effect of anterior chamber depth on endothelial cell count after filtration surgery. Arch Ophthalmol 1989; 107: 1609-1611.

8 Al-Torbak A. Graft survival and glaucoma outcome after simultaneous penetrating keratoplasty and Ahmed glaucoma valve implant. Cornea 2003; 22: 194-197.

9 Coleman AL, Mondino BJ, Wilson MR, Casey R. Clinical experience with the Ahmed Glaucoma Valve implant in eyes with prior or concurrent penetrating keratoplasties. Am J Ophthalmol 1997; 123: 54-61.

10 Bigar F, Witmer R. Corneal endothelial changes in primary acute angle-closure glaucoma. Ophthalmology 1982; 89: 596599.

11 Gagnon MM, Boisjoly HM, Brunette I, Charest M, Amyot M. Corneal endothelial cell density in glaucoma. Cornea 1997; 16: 314-318.

12 Alanko HI, Vuorre I, Saari KM. Characteristics of corneal endothelial cells in Fuchs' heterochromic cyclitis. Acta Ophthalmol (Copenh) 1986; 64: 623-631.

13 Lim KS. Corneal endothelial cell damage from glaucoma drainage device materials. Cornea 2003; 22: 352-354.

14 Kirkness CM, Ling Y, Rice NS. The use of silicone drainage tubing to control post-keratoplasty glaucoma. Eye 1988; 2(Pt 5): 583-590. 
15 Cheng H, Jacobs PM, McPherson K, Noble MJ. Precision of cell density estimates and endothelial cell loss with age. Arch Ophthalmol 1985; 103: 1478-1481.

16 Bourne RR, Minassian DC, Dart JK, Rosen P, Kaushal S, Wingate N. Effect of cataract surgery on the corneal endothelium: modern phacoemulsification compared with extracapsular cataract surgery. Ophthalmology 2004; 111: 679-685.

17 Walkow T, Anders N, Klebe S. Endothelial cell loss after phacoemulsification: relation to preoperative and intraoperative parameters. J Cataract Refract Surg 2000; 26: 727-732.

18 Sihota R, Lakshmaiah NC, Titiyal JS, Dada T, Agarwal HC. Corneal endothelial status in the subtypes of primary angle closure glaucoma. Clin Experiment Ophthalmol 2003; 31: 492-495.

19 Arnavielle S, Lafontaine PO, Bidot S, Creuzot-Garcher C, D'Athis P, Bron AM. Corneal endothelial cell changes after trabeculectomy and deep sclerectomy. J Glaucoma 2007; 16: 324-328.

20 Mencucci R, Ponchietti C, Virgili G, Giansanti F, Menchini U. Corneal endothelial damage after cataract surgery: microincision versus standard technique. J Cataract Refract Surg 2006; 32: 1351-1354.

21 Tsorbatzoglou A, Kertesz K, Modis L, Nemeth G, Math J, Berta A. Corneal endothelial function after phacoemulsification using the fluid-based system compared to conventional ultrasound technique. Eye 2007; 21: 727-732.

22 Sandoval HP, de Castro LE, Vroman DT, Solomon KD. Randomized, double-masked clinical trial evaluating corneal endothelial cell loss after cataract extraction and intraocular lens implantation: fluid-based system versus ultrasound phacoemulsification. Cornea 2006; 25: 1043-1045.

23 Macdonald JM, Geroski DH, Edelhauser HF. Effect of inflammation on the corneal endothelial pump and barrier. Curr Eye Res 1987; 6: 1125-1132.

24 Stave J, Zinser G, Grummer G, Guthoff R. [Modified Heidelberg Retinal Tomograph HRT. Initial results of in vivo presentation of corneal structures]. Ophthalmologe 2002; 99: 276-280.

25 Imre L, Nagymihaly A. Reliability and reproducibility of corneal endothelial image analysis by in vivo confocal microscopy. Graefes Arch Clin Exp Ophthalmol 2001; 239: 356-360.

26 Popper M, Morgado AM, Quadrado MJ, Van Best JA. Corneal cell density measurement in vivo by scanning slit confocal microscopy: method and validation. Ophthalmic Res 2004; 36: 270-276.

27 Klais CM, Buhren J, Kohnen T. Comparison of endothelial cell count using confocal and contact specular microscopy. Ophthalmologica 2003; 217: 99-103.

28 Kitzmann AS, Winter EJ, Nau CB, McLaren JW, Hodge DO, Bourne WM. Comparison of corneal endothelial cell images from a noncontact specular microscope and a scanning confocal microscope. Cornea 2005; 24: 980-984.

29 Szaflik JP. Comparison of in vivo confocal microscopy of human cornea by white light scanning slit and laser scanning systems. Cornea 2007; 26: 438-445.
30 de Sanctis U, Machetta F, Razzano L, Dalmasso P, Grignolo FM. Corneal endothelium evaluation with 2 noncontact specular microscopes and their semiautomated methods of analysis. Cornea 2006; 25: 501-506.

31 Landesz M, Kamps A, Slart R, Siertsema JV, van Rij G. Morphometric analysis of the corneal endothelium with three different specular microscopes. Doc Ophthalmol 1995; 90: 15-28.

32 Benetz BA, Diaconu E, Bowlin SJ, Oak SS, Laing RA, Lass $\mathrm{JH}$. Comparison of corneal endothelial image analysis by Konan SP8000 noncontact and Bio-Optics Bambi systems. Cornea 1999; 18: 67-72.

33 Hara M, Morishige N, Chikama T, Nishida T. Comparison of confocal biomicroscopy and noncontact specular microscopy for evaluation of the corneal endothelium. Cornea 2003; 22: 512-515.

34 Wiegand W, Thaer AA, Kroll P, Geyer OC, Garcia AJ. Optical sectioning of the cornea with a new confocal in vivo slit-scanning videomicroscope. Ophthalmology 1995; 102: 568-575.

35 Chiou AG, Kaufman SC, Beuerman RW, Ohta T, Yaylali V, Kaufman HE. Confocal microscopy in the iridocorneal endothelial syndrome. Br J Ophthalmol 1999; 83: 697-702.

36 Bohnke M, Masters BR. Confocal microscopy of the cornea. Prog Retin Eye Res 1999; 18: 553-628.

37 Chiou AG, Kaufman SC, Kaufman HE, Beuerman RW. Clinical corneal confocal microscopy. Surv Ophthalmol 2006; 51: 482-500.

38 Li J, Jester JV, Cavanagh HD, Black TD, Petroll WM. On-line 3-dimensional confocal imaging in vivo. Invest Ophthalmol Vis Sci 2000; 41: 2945-2953.

39 Kohnen T, Thomala MC, Cichocki M, Strenger A. Internal anterior chamber diameter using optical coherence tomography compared with white-to-white distances using automated measurements. J Cataract Refract Surg 2006; 32: 1809-1813.

40 Dada T, Sihota R, Gadia R, Aggarwal A, Mandal S, Gupta V. Comparison of anterior segment optical coherence tomography and ultrasound biomicroscopy for assessment of the anterior segment. J Cataract Refract Surg 2007; 33: 837840 .

41 Carrillo MM, Trope GE, Pavlin C, Buys YM. Use of ultrasound biomicroscopy to diagnose Ahmed valve obstruction by iris. Can J Ophthalmol 2005; 40: 499-501.

42 Sarodia U, Sharkawi E, Hau S, Barton K. Visualization of aqueous shunt position and patency using anterior segment optical coherence tomography. Am J Ophthalmol 2007; 143: 1054-1056.

43 Memarzadeh F, Li Y, Francis BA, Smith RE, Gutmark J, Huang D. Optical coherence tomography of the anterior segment in secondary glaucoma with corneal opacity after penetrating keratoplasty. Br J Ophthalmol 2007; 91: 189-192.

44 Konstantopoulos A, Hossain P, Anderson DF. Recent advances in ophthalmic anterior segment imaging: a new era for ophthalmic diagnosis? Br J Ophthalmol 2007; 91: 551-557. 